\title{
Health and disease - medical and psychological aspects of quality of life in patients with gynecological cancers
}

Anna Kieszkowska-Grudny, MD PhD

European Health Centre Otwock, Poland Manager: Anna Kieszkowska-Grudny, MD PhD

\begin{abstract}
Gynecological cancers, due to their location and relation to the aspects of femininity, reproductive ability and body image, are associated not only with the physical dimension of cancer, but also with the mental sphere. The loss of fertility may lead to feelings of sadness and grief that remain for a very long time after the treatment. In patients with gynecological cancers, the increased risk of early menopause, loss of femininity, decreased libido, or distorted body image can affect their quality of life. The distress emerging in this situation may further worsen the health condition and negatively affect the quality of life and ability to mobilize the organism to fight against the disease. For this reason, it is important to monitor the level of distress and quality of life using available questionnaires and measurement tools. Psychological interventions and psychotherapy can help women with gynecological cancers raise their self-esteem related e.g. to corporeality, improve the overall quality of life and reduce the psychological distress caused by the disease and the treatment itself.
\end{abstract}

KEY WORDS: gynecological cancers, quality of life, distress ladder, QoL questionnaires 


\section{OVERVIEW OF THE CONCEPTS OF HEALTH AND DISEASE}

Gynecological cancers may be benign (uterine myomas) or malignant tumors. The most frequent gynecological malignant neoplasms are: cervical cancer $(60 \%$ of all the reproductive organ neoplasms), endometrial cancer, ovarian cancer, vulvar cancer, vaginal cancer and cancer of the oviduct [1]. Gynecological cancers are among the most frequent causes of death of postmenopausal women, which is quite a serious social problem. Unfortunately, very often this kind of cancer is diagnosed when the disease is already advanced. In this situation, not only the effectiveness of the treatment is significant, but also the quality of life determined by the health condition, especially that the authors of many studies indicate a high rate of sexual dysfunctions in this patient group (e.g. in women after radiotherapy due to cervical cancer in comparison to patients subjected to surgery), as well as the symptoms of depression or cognitive disorders.

In 1993, the World Health Organization introduced a definition of health which became the point of reference for many other concepts of health and disease. The definition says that health is "an individual's perception of their position in life in the context of the culture and value systems in which they live and in relation to their goals, expectations, standards and concerns". Hence, it is the social, physiological, mental and intellectual well-being of a person [2]. In medical and social sciences, the Health Related Quality of Life (HRQoL) approach was introduced by Schipper in 1990. It means the functional effect of the disease and treatment experienced by the patient [3]. Quality of life perceived this way is the element directly related to the somatic disease but also reflexively affecting its course. This definition includes four basic areas of functioning: physical condition and motor function, mental state, somatic experience and economic conditions [4]. In medical sciences, a broader list of dimensions significant for HRQoL assessment is also used, including: physical well-being, functional well-being, emotional well-being, the ability to maintain family relations and contacts, fulfilling social roles and the resultant satisfaction, satisfaction with the treatment, and the intimate sphere including the image of one's own body [5]. Particularly in the case of gynecological cancers, emotions accompanying the disease play a huge role, the role of social support increases and the sense of quality of life dependent on the intimate and sexual sphere becomes especially significant. The most frequent factors characteristic of the subjective and objective health-related quality of life are presented in Table 1.

Contemporary studies of stress distinguish between eustress, which is essential for the maintenance of a healthy organism, and distress, which is related to unpleasant feelings, for example pain, anxiety or suffering. In patients with gynecological cancers, apart from universal stressors connected with a neoplastic disease, such as the sense of insecurity of life and successive existential crises, there are also ones related to the risk of premature menopause, the loss of femininity understood as the ability to get pregnant and give birth to a healthy baby, but also lower libido, the loss of interest in sex or a distorted image of one's body

TABLE 1.

The most characteristic objective and subjective factors influencing the evaluation of quality of life during the disease.

\begin{tabular}{|c|c|}
\hline Objective factors & Subjective factors \\
\hline $\begin{array}{l}\text { 1. Medical: } \\
\text { - biological factors } \\
\text { - general health condition (results of laboratory tests and specialist } \\
\text { examinations) } \\
\text { - duration and advancement of the disease } \\
\text { - observing doctor's recommendations } \\
\text { - type of treatment } \\
\text { - symptomatic medications } \\
\text { 2. Non-medical: } \\
\text { - social and material status (job, earnings, flat, car) } \\
\text { - change of professional and/or social role } \\
\text { - interpersonal and communication competencies of medical } \\
\text { personnel; the way of diagnosing }\end{array}$ & $\begin{array}{l}\text { - } \text { genetic determinants (temperament) } \\
\text { - } \text { environmental determinants (personality) } \\
\text { - } \text { the level of satisfaction of one's important needs } \\
\text { - } \text { patient's emotional state } \\
\text { - } \text { motivation to active participation in the therapeutic process } \\
\text { - } \text { effectiveness of the applied coping strategies } \\
\text { - individual experience and cultural needs } \\
\text { - faith and spirituality } \\
\text { - perceived social support network, access to self-help groups } \\
\text { - perceived image of one's body }\end{array}$ \\
\hline
\end{tabular}


resulting from gynecological surgeries involving the removal of the whole or a part of the reproductive organ. Distress may lower the person's condition, negatively affect their quality of life and ability of everyday efficient functioning. The disease considerably affects all the spheres of life of a cancer patient, causing huge stress, especially when waiting for a diagnosis. Such a distinction within stress has a very practical dimension, which is reflected in the recommendations issued in 2005 and updated in 2011 by NCCN (National Comprehensive Cancer Network). They recommend screening, routine examination of the level of distress by medical personnel in patients suffering from cancer with the use of so-called distress thermometer [6]. The test is short and simple and therefore recommended as a default procedure in every hospitalized cancer patient. It includes an analogue scale from 0 - no distress, to 10 - extreme distress. If the distress is at the level of 5 or higher, the person should also fill in a chart which allows to specifically identify the areas which cause the greatest negative stress. Practitioners also have guidelines which - after measuring the level - provide recommendations of the ways of coping with this feeling or indicate professional therapeutic methods which can be implemented in the patient (Fig. 1).

Negative stimuli or negative stress can be reflected in the practical - organizational, family, emotional or physical spheres of life, which in the case of women with gynecological cancers may particularly translate into the intimate sphere of life - sexuality, the image of one's body, and the image of femininity, which is reflected in many tools measuring quality of life of this group of women.

\section{TOOLS MEASURING QUALITY OF LIFE IN GYNECOLOGICAL CANCERS}

Questionnaires used to evaluate health-related quality of life applied in medicine and psychology can be divided into general and specific ones. General questionnaires assess the relations between the patient's health status and elements such as emotional state, occupational activity, relations with family and friends etc. Specific questionnaires can be divided into:

FIGURE 1.

Distress ladder and guidelines concerning procedures to be applied (author's own study).

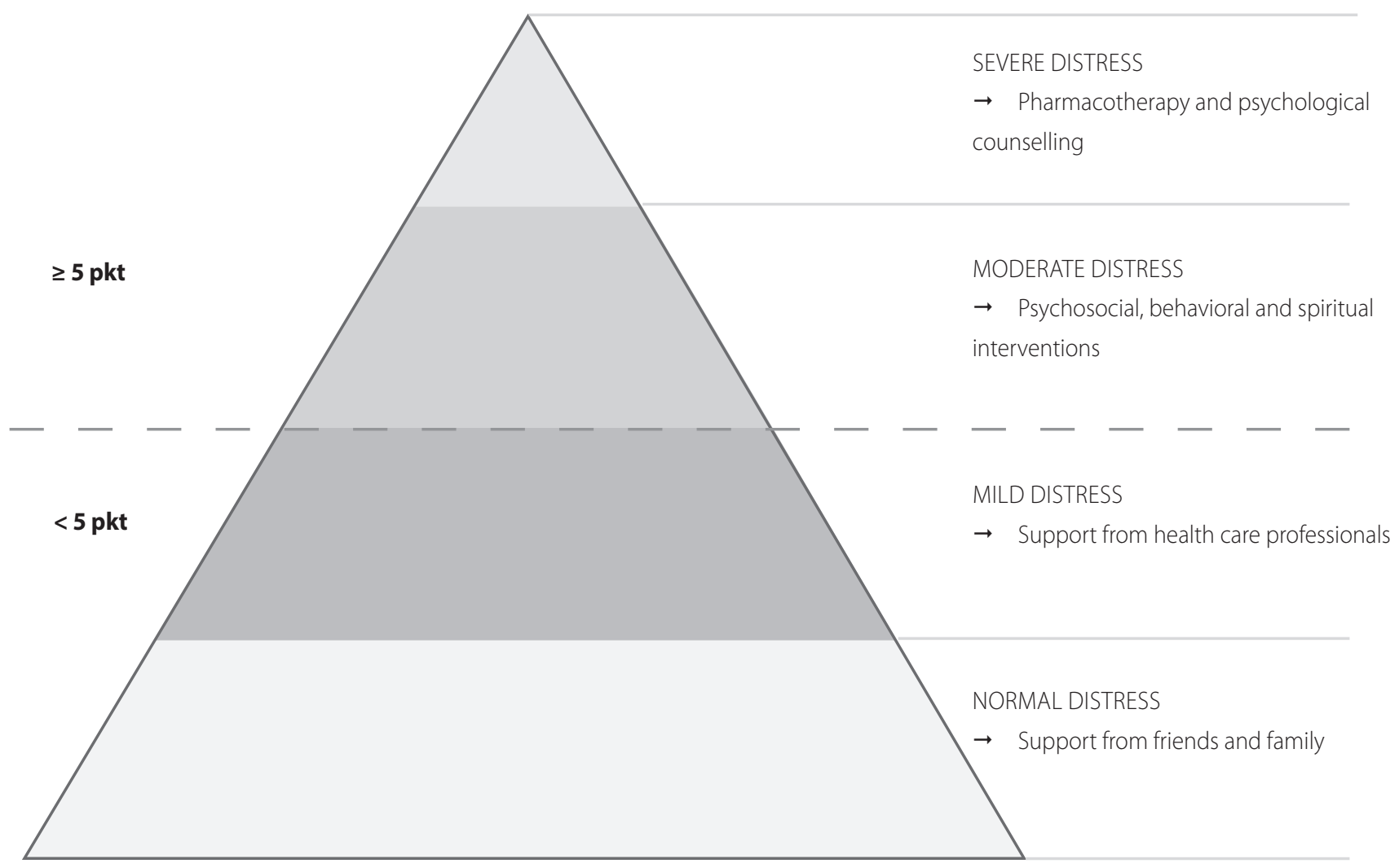


a) concentrating on particular areas of functioning (domain-specific)

b) concerning specific aspects of the disease, determining the intensity of symptoms and the occurrence of side effects (disease-specific)

c) specific for the whole population, e.g. elderly people and children (population-specific)

d) used to assess the quality of life from the perspective of symptoms of the disease (symptom-specific).

Questionnaires evaluating general quality of life of cancer patients most often used in clinical practice and studies include:
ECOG/WHO (Eastern Cooperative Oncology Group and World Health Organisation Performance Status), EORTC QLQ-30 (European Organisation for Research and Treatment of Cancer), FACIT (Functional Assessment of Chronic Illness Therapy Measurement System), FACT-G (Functional Assessment Of Cancer Therapy), GHQ (General Health Questionnaire), SF-36 (Short-Form Health Survey), and many others. Specific questionnaires evaluating quality of life of gynecological cancer patients are focused on symptoms connected with the cancer type and the effect of the disease on the woman's functioning in different areas of life. Examples of selected questionnaires are presented in Table 2.

TABLE 2.

Examples of tests and questionnaires used for the evaluation of quality of life and specific symptoms in patients with gynecological cancers.

\begin{tabular}{|c|c|c|c|}
\hline Test name & Author & Area of concern & Description \\
\hline $\begin{array}{l}\text { BISF-W (Brief Index of Sexual } \\
\text { Functioning for Women) }\end{array}$ & Rosen RC & $\begin{array}{l}\text { Evaluation of current sexual activity of women and } \\
\text { intercourse satisfaction, evaluation covers last } \\
4 \text { weeks. }\end{array}$ & 22 questions \\
\hline $\begin{array}{l}\text { FACT-O (Functional Assessment } \\
\text { of Cancer Therapy Ovarian) }\end{array}$ & Basen-EK et al & $\begin{array}{l}\text { Evaluation of physical, social/family, emotional } \\
\text { and everyday functioning and additional anxieties } \\
\text { connected with ovarian cancer; assessed by the } \\
\text { patient once a week. }\end{array}$ & $\begin{array}{l}27 \text { basic questions of the FACT-G test } \\
\text { and } 12 \text { additional questions; responses } \\
\text { in the } 0-4 \text { (no-very much) scale }\end{array}$ \\
\hline $\begin{array}{l}\text { FACT-Cx (Functional Assessment } \\
\text { of Cancer Therapy - Cervix } \\
\text { Module) }\end{array}$ & Monk BJ & $\begin{array}{l}\text { As above, plus evaluation of symptoms and sexual } \\
\text { difficulties directly related to cervical cancer, } \\
\text { assessed by the patient referring to the last } 7 \text { days. }\end{array}$ & $\begin{array}{l}27 \text { basic questions of the FACT-G test } \\
\text { and } 15 \text { additional questions; responses } \\
\text { in the } 0-4 \text { (no-very much) scale }\end{array}$ \\
\hline $\begin{array}{l}\text { FACT/GOG -AD (Functional } \\
\text { Assessment of Cancer Therapy/ } \\
\text { Gynecologic Oncology Group - } \\
\text { Abdominal Discomfort) }\end{array}$ & Wenzel L et al & $\begin{array}{l}\text { Evaluation of abdominal pain in the course of } \\
\text { ovarian cancer treatment, assessed by the patient. }\end{array}$ & $\begin{array}{l}\text { Evaluation in the scale from } 0 \text { (no pain) } \\
\text { to } 3 \text { (the pain makes it necessary to } \\
\text { administer narcotic analgesics, patient } \\
\text { lying in bed) }\end{array}$ \\
\hline $\begin{array}{l}\text { FOSI/NFOSI (FACT Ovarian } \\
\text { Symptom Index) }\end{array}$ & $\begin{array}{l}\text { Beaumont J } \\
\text { et al } \\
\text { Jensen SE et al }\end{array}$ & $\begin{array}{l}\text { Evaluation of symptoms related to ovarian cancer, } \\
\text { concerning ailments depending on the disease } \\
\text { and on the treatment; assessed by the patient. }\end{array}$ & $\begin{array}{l}\text { An 8-item scale, in modified version: } \\
\text { an 18-item scale with } 3 \text { subscales: } \\
\text { disease symptoms, treatment and } \\
\text { general functioning }\end{array}$ \\
\hline $\begin{array}{l}\text { MFSQ (McCoy Female Sexuality } \\
\text { Questionnaire) }\end{array}$ & McCoy NL & $\begin{array}{l}\text { A scale evaluating HRQoL (including health } \\
\text { condition) as well as objective and subjective } \\
\text { symptoms of gynecological diseases, among } \\
\text { others feminine sexuality, biological aspects of the } \\
\text { disease; assessed by the patient every } 4 \text { weeks. }\end{array}$ & $\begin{array}{l}\text { The basic version includes } \\
19 \text { questions concerning sexuality; } \\
\text { also available in a shortened version } \\
\text { with } 7,9 \text { or } 17 \text { questions }\end{array}$ \\
\hline QOL-CX 24 EORTC & $\begin{array}{l}\text { EORTC Quality } \\
\text { of Life Group }\end{array}$ & $\begin{array}{l}\text { Module prepared to evaluate symptoms specific in } \\
\text { cervical cancer, including aspects connected with } \\
\text { sexual life; assessed by the patient every week and } \\
\text { every month. }\end{array}$ & $\begin{array}{l}24 \text { questions in } 3 \text { groups: symptoms, } \\
\text { the image of one's body, sexual } \\
\text { activity; responses } 1-4\end{array}$ \\
\hline QOL-OV 28 EORTC & $\begin{array}{l}\text { EORTC Quality } \\
\text { of Life Group }\end{array}$ & $\begin{array}{l}\text { Evaluation of the intensity of symptoms and } \\
\text { anxieties connected with ovarian cancer, including } \\
\text { aspects connected with sexual life; assessed by the } \\
\text { patient every week and every month. }\end{array}$ & $\begin{array}{l}28 \text { questions in } 3 \text { groups: symptoms, } \\
\text { the image of one's body, sexual } \\
\text { activity; responses } 1-4\end{array}$ \\
\hline $\begin{array}{l}\text { UFS - QOL (Uterine Fibroid } \\
\text { Symptom and Quality of Life } \\
\text { Questionnaire) }\end{array}$ & Spies JB & $\begin{array}{l}\text { Evaluation of the intensity of symptoms and their } \\
\text { impact on quality of life in patients with uterine } \\
\text { myomas; assessed by the patient every quarter. }\end{array}$ & 37 questions \\
\hline
\end{tabular}




\section{EVALUATION OF QUALITY OF LIFE IN GYNECOLOGICAL CANCERS VERSUS TREATMENT TYPES}

Gynecological cancers include all the neoplasts of female reproductive organs - oviducts, ovaries, uterine body, uterine cervix, vagina or vulva. They can be divided into cancers of the upper (oviducts, ovaries) and lower (endometrium, cervix, vagina and vulva) reproductive tract, leading to certain consistency but also certain differences in the image of the disease and associated symptoms. The same refers to the perceived quality of life. As presented above, many objective and subjective factors can affect the quality of life of gynecological patients. These can both be factors connected with the disease itself, its intensity and advancement, with the disease symptoms, as well as with the diagnostic process and the applied therapy.

In women fighting with gynecological cancers, sexual function is usually the most impaired area of quality of life [7]. These problems may result from physiological, anatomical or psychological factors, but usually these factors are combined [8]. Anxiety and depression occurring along with stress and tiredness connected with long-lasting diagnosing and treatment of cancer may reduce the women's libido and ability of sexual arousal. The issues related to sexuality, e.g. self-esteem and evaluation of one's sexuality, may also mentally limit sexual activity [9], and a positive evaluation of one's appearance and "feeling to be a woman" were proved to be related with higher sexual activity in women who had been ill with ovarian cancer [10]. The author's own research showed that quality of life on patients with cervical cancer was surprisingly similar to that of healthy women. It was also found that half as many women with cancer had had intercourse during the previous month than healthy women ( $38 \%$ vs $66 \%$; $p<0,05)$. Nearly $50 \%$ of women after the treatment do not feel like having sex, which may be connected with continuous ailments in the area of vulva and vagina and pain during the intercourse. The treatment significantly affects self-esteem, and women who have undergone cervical cancer treatment perceive themselves as less feminine and less physically attractive than healthy women [11].

Anxieties related to the maintenance of fertility are also closely associated with reduced quality of life [12]. Coping with a situation of cancer diagnosis, connected with existential crisis, as well as the risk of infertility occurring at the same time, are very often perceived as "double trauma", which increases the patients' susceptibility to mental distress [13]. The loss of fertility may lead to feelings of sadness and grief that remain for a very long time after the treatment. What is more, these feelings may intensify when the primary threat of life disappears after the treatment. In women who are able to get pregnant after a neoplastic disease, physical, emotional and financial burdens may make it difficult to cure infertility. Apart from that, the pregnancy is often at risk and requires special management. In addition, those women have a high level of "triple anxiety", i.e. anxiety about their own health during pregnancy, anxiety that the potential maternity may be disturbed by a relapse of the cancer, and the risk that the babies will inherit the disease.

Generally, studies taking into account different methods of treatment of gynecological cancers proved that surgery has the best impact on the quality of life of the patients, radiotherapy has a little worse impact and the greatest negative impact on quality of life is observed after chemotherapy [14-16]. Regarding surgery, it must be emphasized that many new techniques, e.g. laparoscopy or endoscopy, shorten the duration and scope of operations and the time of full recovery. That is why in this case the quality of life is also quickly restored to the initial level, or even higher, as a result of redefinition of values and a new prospect of life developed by the women after the disease $[17,18]$. Besides, in many patients, e.g. after massive pelvis exaggeration, the quality of life was comparable to that of healthy women, despite many physical and social problems as well as sexual disorders, insomnia and tiredness. This effect can be explained with the perceived high life threat, of which the women were aware, and the ultimate positive effect of radical surgery. Radiotherapy is particularly connected with various ailments, such as tiredness, pain, urinary bladder dysfunctions or dryness and irritation of the vagina, as well as its narrowing or fibrosis, which not only affect sexual activity but also lead to discomfort during gynecological exams [11, 19], so most women very poorly evaluate the quality of life during, and especially at the end and after, such therapy. Chemotherapy may have both a positive and negative effect on the quality of life of patients with gynecological cancers. It improves the quality of life by reducing symptoms but also causes slowing down, stopping or regression of the neoplastic process, and thus it improves the patients' functioning. The negative impact on the quality of life is usually connected with the occurrence of many adverse effects. The most unpleasant adverse effects affecting the quality of life during the disease, identified by the patients, include nausea, vomiting, tiredness, hair loss, the influence of the disease on the family, depression, anxiety connected with the treatment, sleeping difficulties, the feeling of anxiety/tension connected with the inserted cannulas, needles, ports etc. [20-22].

To sum up, contemporary medicine more and more often cooperates with psychology in order to ensure even better diagnosis and treatment for oncological patients, and thus maintain or even increase the quality of life during the disease. Treatment methods which are less invasive and connected with lower risk of adverse 
effects have a beneficial effect on future results but also help induce psychologically, emotionally and socially positive life in the sufferers. In the modern approach to psycho-oncological care, the distress related to the diagnostic process itself and waiting for the diagnosis must not be ignored either. Therefore, everyday practice should involve modern and early diagnostic methods such as liquid base cytology, genetic tests, precise imaging (e.g. high tesla MRI) but also quick histopathologic tests which allow for shortening the diagnosis to the necessary minimum, firstly to start effective treatment as quickly as possible but primarily to reduce the anxiety, tension and fear which occur when waiting for the diagnosis of cancer, which is the source of a lower quality of life.

\section{References}

1. Krajowy Rejestr Nowotworów [online: http://85.128.14.124//krn/].

2. World Health Organization. WHOQoL Study Protocol. WHO 1993.

3. Schipper H. Quality of life: principles of the clinical paradigm. Journal of Psychology 1990; 23(8): 171-185.

4. Streuden S, Okła W. Jakość życia w chorobie. Wydawnictwo KUL, Lublin 2007.

5. Peterman AH, Cella D. Quality of life. In: Kazdin AE (ed.). Encyclopedia of Psychology. Oxford University Press - American Psychology Association 2000; 6: 445-456

6. National Comprehensive Cancer Network. Distress Treatment Guidelines for Patients. Version 1.2011. NCCN 2011, Rockledge, Pennsylvania [online: www.nccn.org/professionals/physician_gls/pdf/distress.pdf].

7. Bodurka DC, Sun CC. Sexual function after gynecologic cancer. Obstetrics \& Gynecology Clinics of North America 2006; 33(4): 621-630.

8. Penson RT, Wenzel LB, Vergote I et al. Quality of life considerations in gynecologic cancer. FIGO 6th Annual Report on the Results of Treatment in Gynecological Cancer. International Journal of Gynecology \& Obstetrics 2006; 95(suppl 1): 247-257.

9. Stead ML. Sexual dysfunction after treatment for gynaecologic and breast malignancies. Current Opinion in Obstetrics \& Gynecology 2003; 15(1): 57-61.

10. Carmack Taylor CL, Basen-Engquist K, Shinn EH et al. Predictors of sexual functioning in ovarian cancer patients. Journal of Clinical Oncology 2004; 22(5): 881-889.

11. Kieszkowska-Grudny A, Rucińska M, Biedrzycka S et al. Ocena jakości życia w grupie kobiet chorych na raka szyjki macicy po radykalnej radiochemioterapii oraz w grupie kobiet nieleczonych z powodu raka - doniesienie wstępne. Nowotwory. Journal of Oncology 2012; 62(3): $101-107$.

12. Wenzel L, Dogan-Ates A, Habbal R et al. Defining and measuring reproductive concerns of female cancer survivors. Journal of the National Cancer Institute 2005; 34: 94-98.

13. Carter J, Lewin S, Abu-Rustum N et al. Reproductive issues in the gynecologic cancer patient. Oncology, Huntington 2007; 21(5): 598-606.

14. Vistad I, Fossa SD, Dahl AA. A critical review of patient-rated quality of life studies of long-term survivors of cervical cancer. Gynecologic Oncology 2006; 102(3): 563-572

15. Vaz AF, Pinto-Neto AM, Conde DM et al. Quality of life and acute toxicity of radiotherapy in women with gynecologic cancer: A prospective longitudinal study. Archives of Gynecology and Obstetrics 2008; 278: 215-223.

16. Jones GL, Ledger W, Bonnett TJ et al. The impact of treatment for gynecological cancer on health-related quality of life (HRQoL): a systematic review. American Journal of Obstetrics \& Gynecology 2006; 194(1): 26-42.

17. Medeiros LR, Rosa DD, Bozzetti MC et al. Laparoscopy versus laparotomy for benign ovarian tumour. Cochrane Database Systematic Review 2009 (2): CD004751.

18. Ramshaw BJ. Laparoscopic Surgery for Cancer Patients. CA - A Cancer Journal for Clinicians 1997; 7(6): 327-350.

19. Akyüz A, Güvenç G, Ustünsöz A et al. Living with gynecologic cancer: experience of women and their partners. Journal of Nursing Scholarship 2008; 40(3): 241-7.

20. Griffin AM, Butow PN, Coates AS et al. On the receiving end. V: Patient perceptions of the side effects of cancer chemotherapy in 1993 . Annals of Oncology 1996; 7(2): 189-195.

21. de Boer-Dennert M, de Wit R, Schmitz PI et al. Patient perceptions of the sideffects of chemotherapy: the influence of $5 \mathrm{HT} 3$ antagonists. British Journal of Cancer 1997; 76(8): 1055-61

22. Lindley C, McCune JS, Thomason TE et al. Perception of chemotherapy side effects cancer versus noncancer patients. Cancer Practice 1999; 7(2): 59-65.

Correspondence:

Anna Kieszkowska-Grudny, MD PhD

European Health Centre Otwock

05-400 Otwock, ul. Borowa 18/18, Poland

tel.: (+48) 22 710-30-54

e-mail: anna.kieszkowska@gmail.com 